\title{
Chlorin e6-Biotin Conjugates for Tumor-Targeting Photodynamic Therapy
}

\author{
Wei Liu ${ }^{1,+}$, Xingqun Ma ${ }^{2,+}$, Yingying Jin ${ }^{1}$, Jie Zhang ${ }^{1}$, Yang Li $^{1}$, Yuxia Tang ${ }^{1, *}$, Yong Song ${ }^{3, *}$ \\ and Shouju Wang $1, *$ (D) \\ 1 Lab of Molecular Imaging, Department of Radiology, the First Affiliated Hospital of Nanjing Medical \\ University, Nanjing 210000, China; njmu_lw@163.com (W.L.); yingyingjin@njmu.edu.cn (Y.J.); \\ zhangjiegxf@163.com (J.Z.); yang.li@njmu.edu.cn (Y.L.) \\ 2 Department of Oncology, Nanjing Baiyi Hospital, Jinling Clinical College of Nanjing Medical University, \\ Nanjing 210000, China; maxingqun@126.com \\ 3 Department of Respiratory and Critical Care Medicine, Jinling Clinical College of Nanjing Medical University, \\ Nanjing 210000, China \\ * Correspondence: tangyuxia5@163.com (Y.T.); yong_song6310@yahoo.com (Y.S.); \\ shouju.wang@gmail.com (S.W.) \\ $+\quad$ These authors contributed equally.
}

check for updates

Citation: Liu, W.; Ma, X.; Jin, Y.; Zhang, J.; Li, Y.; Tang, Y.; Song, Y.; Wang, S. Chlorin e6-Biotin Conjugates for Tumor-Targeting Photodynamic Therapy. Molecules 2021, 26, 7342. https://doi.org/10.3390/ molecules 26237342

Academic Editors: Paola Barraja,

Alessandra Montalbano,

Virginia Spanò and M. Graça P. M. S. Neves

Received: 25 October 2021

Accepted: 29 November 2021

Published: 3 December 2021

Publisher's Note: MDPI stays neutral with regard to jurisdictional claims in published maps and institutional affiliations.

Copyright: (c) 2021 by the authors. Licensee MDPI, Basel, Switzerland. This article is an open access article distributed under the terms and conditions of the Creative Commons Attribution (CC BY) license (https:/ / creativecommons.org/licenses/by/ $4.0 /)$.

\begin{abstract}
To improve the tumor-targeting efficacy of photodynamic therapy, biotin was conjugated with chlorin e6 to develop a new tumor-targeting photosensitizer, Ce6-biotin. The Ce6-biotin had good water solubility and low aggregation. The singlet-oxygen generation rate of Ce6-biotin was slightly increased compared to Ce6. Flow cytometry and confocal laser scanning microscopy results confirmed Ce6-biotin had higher binding affinity toward biotin-receptor-positive HeLa human cervical carcinoma cells than its precursor, Ce6. Due to the BR-targeting ability of Ce6-biotin, it exhibited stronger cytotoxicity to HeLa cells upon laser irradiation. The IC50 against HeLa cells of Ce6-biotin and Ce6 were $1.28 \mu \mathrm{M}$ and $2.31 \mu \mathrm{M}$, respectively. Furthermore, both Ce6-biotin and Ce6 showed minimal dark toxicity. The selectively enhanced therapeutic efficacy and low dark toxicity suggest that Ce6-biotin is a promising PS for BR-positive-tumor-targeting photodynamic therapy.
\end{abstract}

Keywords: biotin; photosensitizer; chlorin e6; photodynamic therapy

\section{Introduction}

Photodynamic therapy (PDT) is based on the local activation of photosensitizers (PSs) in tumors to induce chemical damage, leading to tumor cell death [1,2]. This method has become a clinically promising approach for treatment of cancers and a wide range of other diseases. Upon irradiation, the PSs activate oxygen to the singlet state and damage the nearby cells [3-5]. Compared with ultraviolet or visible light, near-infrared (NIR) light has deeper penetration into the normal tissues and has great potential in PDT for deep tumors [6]. However, PSs may accumulate in healthy tissues and cause various side effects, such as pain and photoallergic reactions [4,7]. Up to now, the poor selectivity of PSs to tumors is still an obstacle that severely limits their clinical application in PDT [8,9]. Therefore, much research has been devoted to improving the targeting ability of PSs.

The targeting efficacy of PDT is contingent on the relative abundance of PSs in tumor lesions compared to the surrounding normal tissues [10]. Selective toxicity would be achieved if PSs were delivered to specific membrane receptors of target cells with the aid of complementary targeting moieties (antibodies, saccharides, hormones, lectins). By illuminating the target area only, dual-specificity would be achieved by the specific distribution of PSs and the spatial control of the irradiation field [10,11]. Combining targeting ligands with PSs is a promising strategy to achieve tumor-specific distribution. Biotin (vitamin B7) is one of the excellent targeting ligands to target cancer cells. Various cancer cells, such as cervical, breast, lung, and ovarian, overexpress biotin receptors [12-14]. Thus, biotin 
has been combined with various fluorescent materials to improve the efficiency of cell labeling and bioimaging [15]. Nilesh et al. [14] designed biotin-tagged nanocarriers for drug delivery. Their results showed significantly higher accumulation of nanocarriers in biotin-receptor-overexpressed cervical cancer cells (HeLa) through the receptor-assisted endocytosis process, which significantly enhanced the therapeutic effect on cancer cells. Moreover, the chemical structure of the biotin molecule is composed of two rings and a valeric acid moiety attached as a side chain. The valeric acid moiety enables biotin to participate in various syntheses [16]. A few PSs, like methyl-pheophorbide and phthalocyanine, have been conjugated to biotin and showed improved therapeutic efficacy to biotin-receptor- (BR) positive cancer cells $[17,18]$.

One of the most widely used PSs is Chlorin e6 (Ce6). Ce6 has the following advantages: rapid clearance [17], high singlet-oxygen-generation efficiency [19], NIR light excitation [20], and fluorescence imaging capability [21]. Ce6 is currently under clinical trials for the treatment of esophagus, bladder, skin, head, and neck cancers [22]. Ce6 and its conjugates are minimally toxic in the dark; however, the biodistribution of Ce6 in the body is nonspecific and may induce photosensitivity reactions when patients are exposed to sunlight. Therefore, the targeted delivery of Ce6 is highly desirable.

In this work, we conjugated biotin with Ce6 to synthesize tumor-targeting PSs and to increase its therapeutic efficacy to BR-positive cancer cells. The water solubility and singlet-oxygen-generating ability of Ce6-biotin were measured. The targeting ability, PDT activities and dark toxicity of Ce6-biotin were tested in a BR-positive cell line (HeLa cell). The experimental results show that Ce6-biotin is a potential tumor-targeting PS for PDT.

\section{Results and Discussion}

\subsection{Synthesis of Ce6-Biotin}

Scheme 1 shows the synthetic route of Ce6-biotin. A Boc-protected amino group was linked to the biotin molecule to obtain compound 2 through Ethyl-3-(3-dimethylaminopropyl) carbodiimide hydrochloride (EDCI) reaction. Then, the amino group was de-protected (compound 3) and linked to the carboxyl group on Ce6 to obtain Ce6-biotin. The reaction is selective to the middle carboxyl group due to its high reactivity [23]. The ${ }^{1} \mathrm{H}-\mathrm{NMR}$ of Bocprotected biotin and Ce6-biotin and the HR-MS of Ce6-biotin are available in Supplementary Material (Figures S1-S3).

\subsection{Photophysical Properties of Ce6-Biotin}

To evaluate the photophysical properties of Ce6-biotin, ultraviolet-visible spectroscopy (UV-vis spectra) of Ce6-biotin was investigated both in phosphate buffer saline (PBS) and dimethyl sulfoxide (DMSO). The UV-vis spectra of Ce6 and Ce6-biotin at different concentrations are shown in Figure 1. The Q-bands of both Ce6 and Ce6-biotin strictly obey the Lambert-Beer law. The UV-vis spectra in DMSO and PBS indicate a typical absorption of non-aggregated Ce6, displaying a narrow and strong Soret band at $406 \mathrm{~nm}$ in DMSO and $402 \mathrm{~nm}$ in PBS, respectively, along with a Q-band at $655 \mathrm{~nm}$. The absorption spectra in PBS are similar to those in DMSO, which has just a $4 \mathrm{~nm}$ red shift of the Q-band. As aggregation is concentration-dependent, the relationship between the UV-vis spectra and the concentrations of Ce6-biotin was also investigated. No new bands appear, with the concentration varying from 0.5 to $10 \mu \mathrm{M}$ in PBS, further proving that Ce6-biotin is nonaggregated in PBS. The lower absorbance of Ce6 and Ce6-biotin in PBS is probably due to the solute-solvent interaction [24]. The non-aggregated state of PSs is very important for their PDT efficiency because aggregation of PSs may inhibit the generation efficiencies of ROSs $[10,25,26]$. 


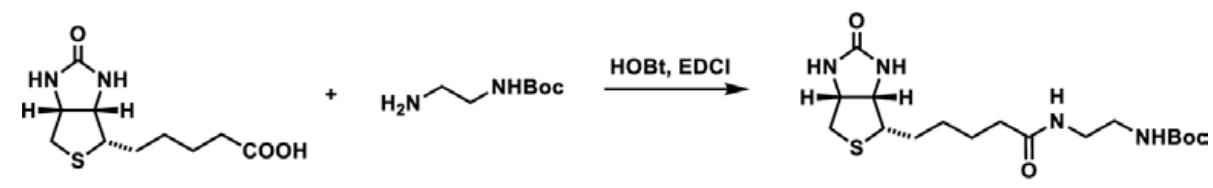

1

2<smiles>Cc1ccccc1NCCNC(=O)CCCC[C@H]1SC[C@@H]2NC(=O)N[C@@H]21</smiles>
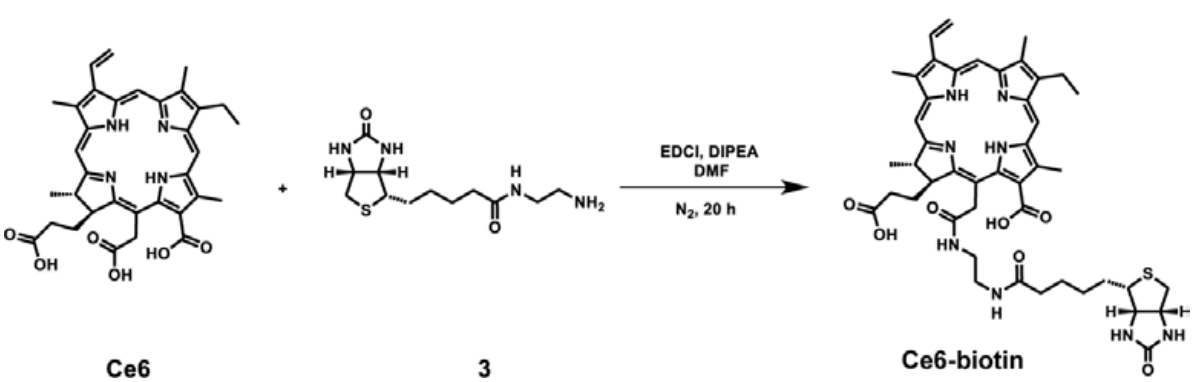

Scheme 1. Synthesis of Ce6-biotin.

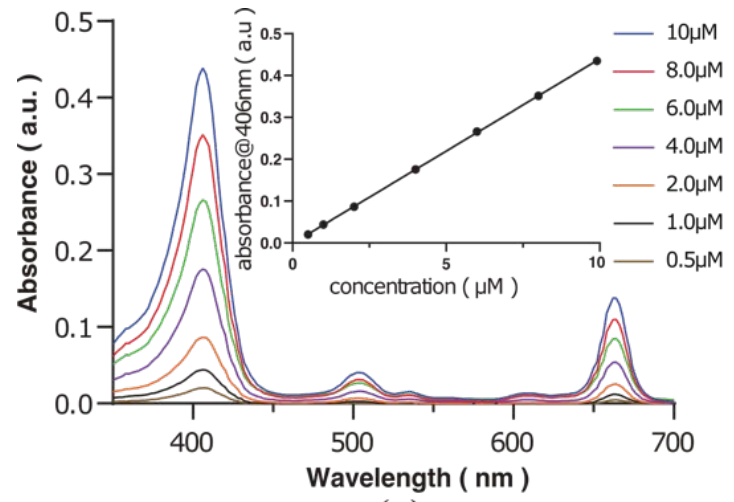

(a)

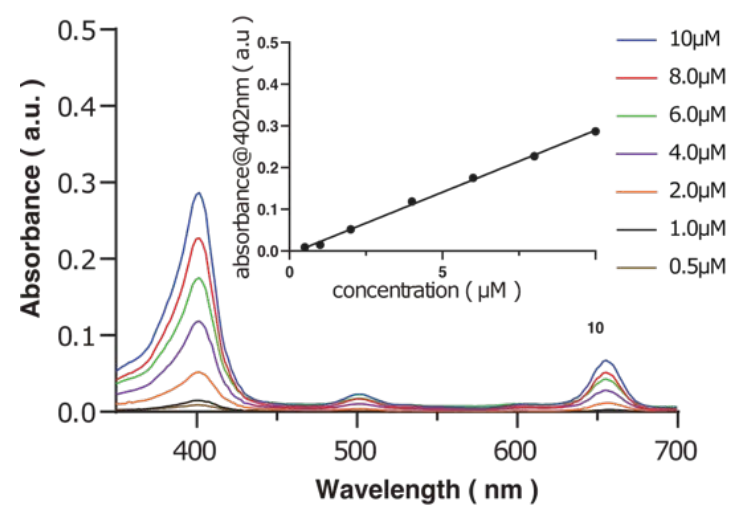

(c)

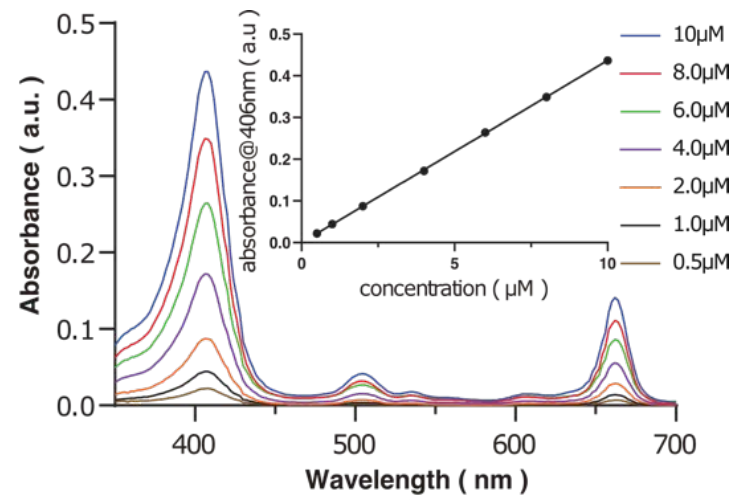

(b)

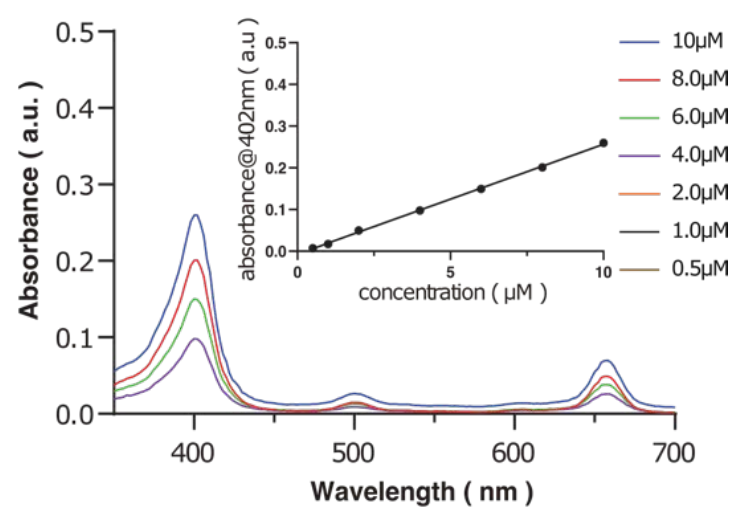

(d)

Figure 1. UV-Vis spectra of Ce6 in DMSO (a) and PBS (c), as well as Ce6-biotin in DMSO (b) and PBS (d). The insets plot the absorbance of the Q-band versus the concentration of Ce6 and Ce6-biotin. 
The fluorescence of Ce6 and Ce6-biotin in PBS was compared. Upon excitation at $400 \mathrm{~nm}$, Ce6 shows fluorescence emission peaks at $663 \mathrm{~nm}$ in PBS and $670 \mathrm{~nm}$ in DMSO, while Ce6-biotin shows fluorescence emission peaks at $665 \mathrm{~nm}$ in PBS and 668 in DMSO. The absorption spectrum and the fluorescence intensity remained virtually the same (Figure 2). The fluorescence of Ce6-biotin is only a little weaker than that of Ce6, probably because the modification did not alter the basic structure of Ce6. Considering its intense fluorescence emission in the infrared region, Ce6-biotin may also serve as a fluorescent probe for in vivo application [27].

PBS

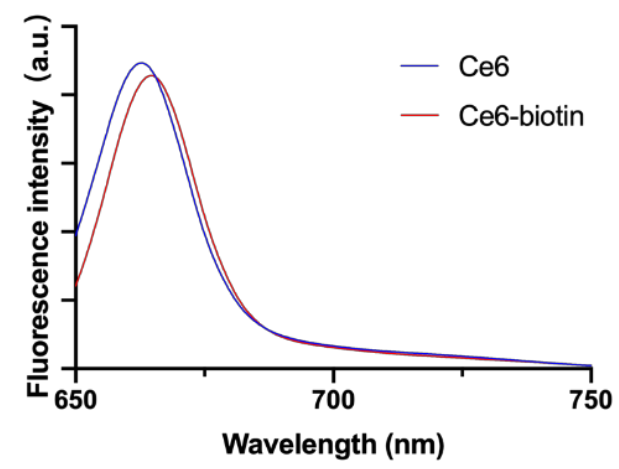

(a)
DMSO

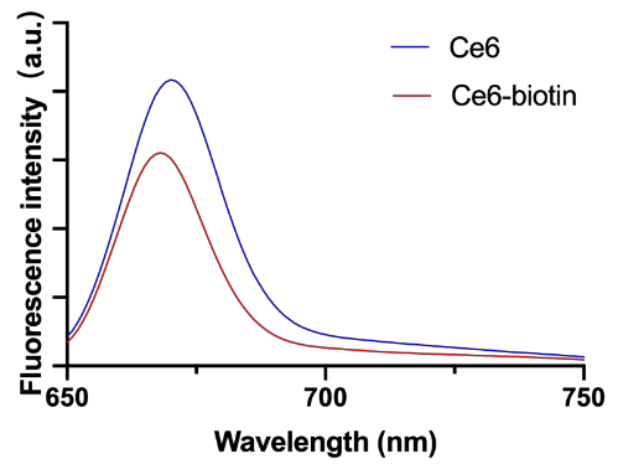

(b)

Figure 2. Fluorescence spectra of Ce6 and Ce6-biotin $(2 \mu \mathrm{M})$ in PBS (a) and DMSO (b).

\subsection{Detecting Singlet-Oxygen Generation In Vitro}

The singlet-oxygen-generating efficiency of Ce6-biotin was measured by the Singlet Oxygen Sensor Green (SOSG) assay. Upon the presence of ${ }^{1} \mathrm{O}_{2}$, the intrinsic fluorescence of SOSG in PBS is restored, resulting in increased fluorescence with laser irradiation time. As shown in Figure 3, Ce6-biotin was an efficient singlet-oxygen generator, and the efficiency was similar to Ce6. It shows that the introduction of biotin will not affect the ability of Ce6 to produce singlet oxygen. The PDT efficiency of PSs is highly dependent on their singlet-oxygen generation abilities [28,29]. As shown in Table 1 , the ${ }^{1} \mathrm{O}_{2}$ quantum yield of Ce6-biotin $\left(\Phi_{\Delta}=0.81\right)$ is slightly higher than that of Ce6 $\left(\Phi_{\Delta}=0.75\right)$, which might be attributed to the large conjugation of the porphyrinic system [10,30]. All these results clearly indicate the singlet-oxygen generation ability of Ce6-biotin.

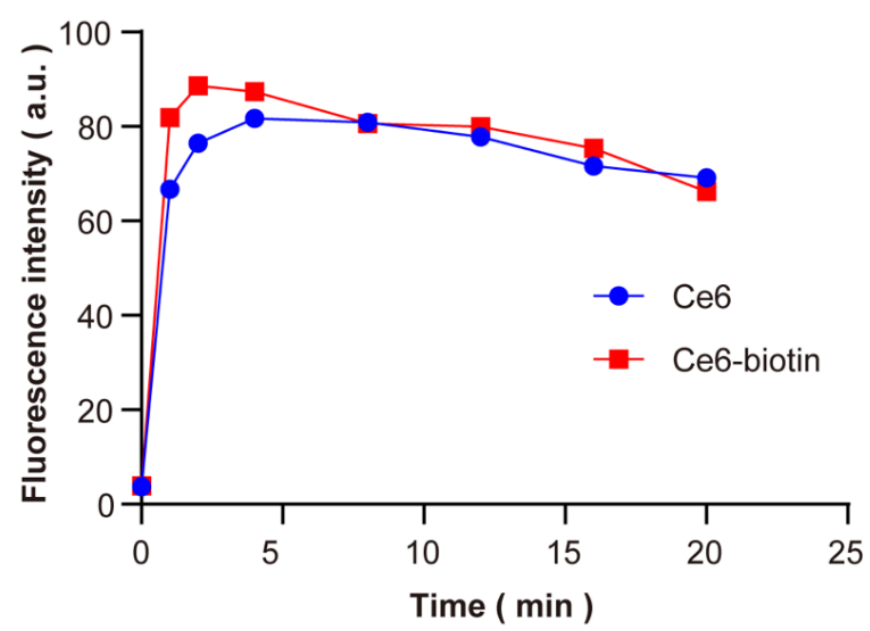

Figure 3. Comparison of the fluorescence of SOSG at $530 \mathrm{~nm}$ in PBS using Ce6 and Ce6-biotin as photosensitizers after being irradiated by $660 \mathrm{~nm}\left(1 \mathrm{~W} \cdot \mathrm{cm}^{-2}\right)$ laser up to $20 \mathrm{~min}$. 
Table 1. Photochemical data for Ce6 and Ce6-biotin.

\begin{tabular}{cccc}
\hline & $\lambda_{\text {abs }}(\mathbf{n m})$ & $\lambda_{\text {em }}(\mathbf{n m})^{\mathbf{a}}$ & $\boldsymbol{\Phi}_{\Delta}{ }^{\mathbf{b}}$ \\
\hline Ce6 & 406 & 663 & 0.75 \\
Ce6-biotin & 402 & 665 & 0.81 \\
\hline
\end{tabular}

axcited at $400 \mathrm{~nm} .{ }^{\mathrm{b}}$ Referenced by Ce6 $\left(\Phi_{\Delta}=0.75\right.$ in PBS).

\subsection{Cellular Uptake of Ce6-Biotin}

The cellular uptake of Ce6 and Ce6-biotin in HeLa cells was investigated by a flowcytometry collection method since biotin receptors are overexpressed in HeLa cells. PSs $(2 \mu \mathrm{M})$ were incubated with HeLa cells for different times $(0.5,1,2,4$ and $6 \mathrm{~h})$. After incubation, the internalized PSs were quantified by flow cytometer. As shown in Figure $4 \mathrm{a}$, the uptake of Ce6-biotin in HeLa cells is significantly higher than that of Ce6 for $6 \mathrm{~h}$. After quantitative analysis (Figure 4b), the cellular uptake of Ce6-biotin after $6 \mathrm{~h}$ incubation is about 4 times higher than that of Ce6. The rapid differentiation of Ce6 and Ce6-biotin in cellular uptake supports the assumption that conjugation of Ce6 with biotin molecules can enhance the association of Ce6 toward BR-positive HeLa cells.

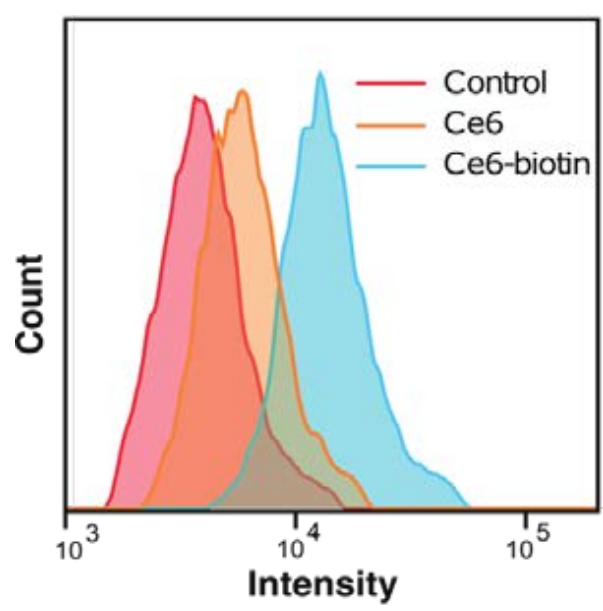

(a)

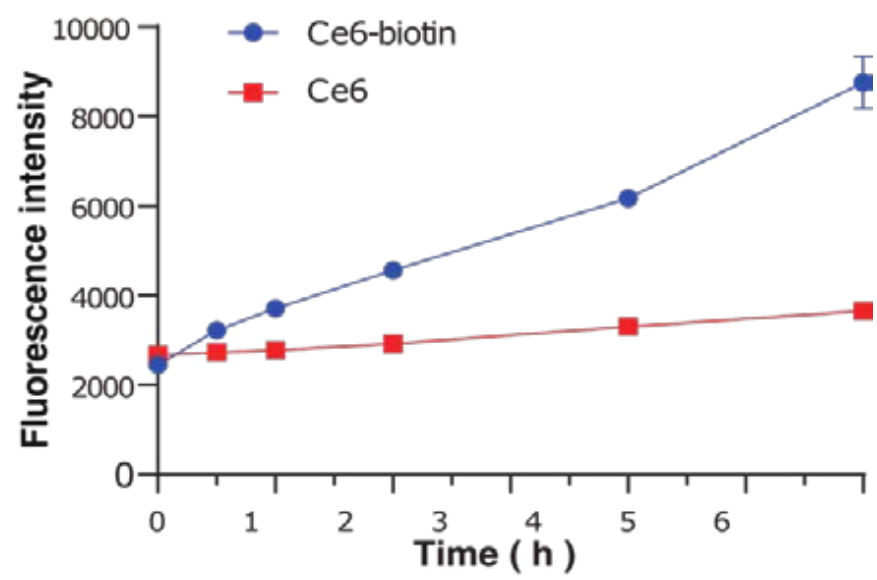

(b)

Figure 4. (a) Flow cytometry analyses of HeLa cells incubated with Ce6 and Ce6-biotin for 6 h. (b) Uptake isotherms of Ce6 and Ce6-biotin toward HeLa cells incubated for $0.5,1,2,4$, and $6 \mathrm{~h}$, respectively.

The cellular uptake of Ce6-biotin was also visualized by confocal fluorescence imaging. The fluorescence images were obtained for both Ce6- and Ce6-biotin-treated cells after $6 \mathrm{~h}$ (Figure 5). It is shown that both Ce6 and Ce6-biotin were internalized by HeLa cells. It is noted that the intracellular fluorescence intensity of Ce6-biotin was higher than that of Ce6, which is in line with the observed higher uptake of Ce6-biotin than Ce6 in HeLa cells.

\subsection{Therapeutic Efficacy and Dark Cytotoxicity of Ce6-Biotin}

In order to measure the therapeutic efficacy and dark cytotoxicity of Ce6 and Ce6biotin, the 3-(4,5-dimethylthiazol-2-yl)-2,5-diphe-yltetrazolium bromide (MTT) assay was used to determine the viability of the cells treated with the two PSs. The cells treated at zero concentration were set as control groups. Without irradiation, Ce6 and Ce6-biotin showed minimal cytotoxicity to HeLa cells at concentrations between 0.25 and $4 \mu \mathrm{M}$ (Figure 6a). After irradiation, both Ce6 and Ce6-biotin exhibited concentration-dependent cytotoxicity. The assays showed the viability of HeLa cells decreased from $100 \pm 9.57 \%$ of the blank control to $1.83 \pm 0.08 \%$ (Ce6) and $4.72 \pm 1.03 \%$ (Ce6-biotin) after laser irradiation, as the Ce6 and Ce6-biotin concentration increased from 0.25 to $4.0 \mu \mathrm{M}$ (Figure $6 \mathrm{~b}$ ). It is noted that at concentrations from $1.0 \mu \mathrm{M}$ to $2.0 \mu \mathrm{M}$, the therapeutic efficacy of Ce6-biotin is significantly higher than that of $\mathrm{Ce} 6$ at the same concentration. At concentrations of $4.0 \mu \mathrm{M}$, 
the therapeutic efficacy of Ce6 is significantly higher than that of Ce6-biotin. This is in line with the observed higher uptake of Ce6-biotin than Ce6 in HeLa cells. The calculated IC 50 of Ce6 is $2.31 \mu \mathrm{M}$-higher than that of Ce6-biotin $(1.28 \mu \mathrm{M})$. Furthermore, the cytotoxicity of Ce6-biotin was tested in HeLa (BR+) and B16 (BR-) cells both with and without irradiation. As shown in Figure 7, Ce6-biotin exhibited higher cytotoxicity to HeLa cell than to B16 cells after treatment with the same light dose $\left(20 \mathrm{~J} \cdot \mathrm{cm}^{-2}\right)$ and Ce6-biotin concentration $(2.0 \mu \mathrm{M})$. These results indicate that the Ce6-biotin can enhance the therapeutic effect on BR-positive cancer cells without increasing dark cytotoxicity.

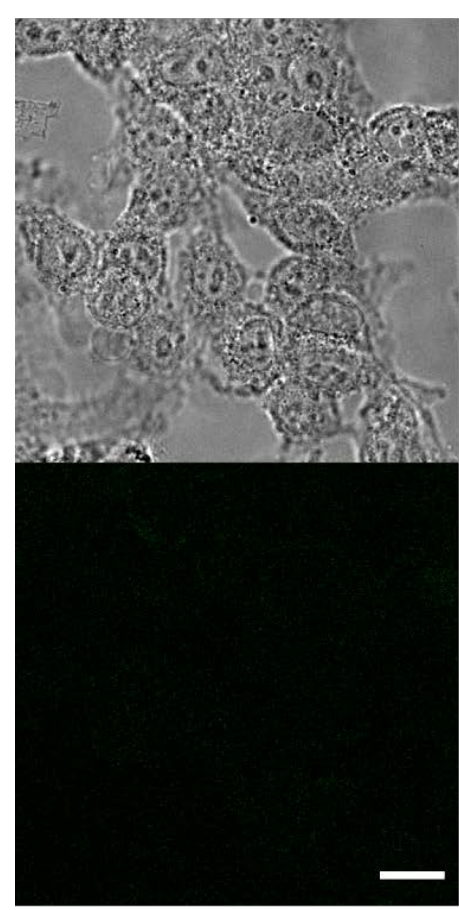

(a)

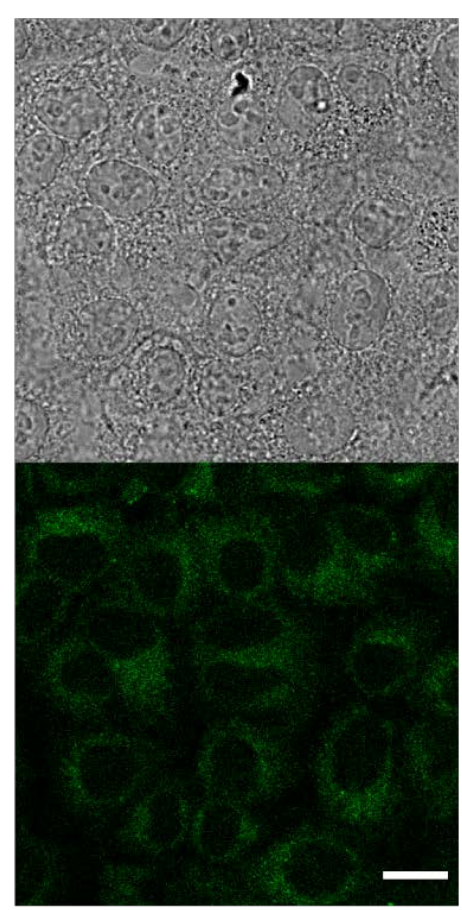

(b)

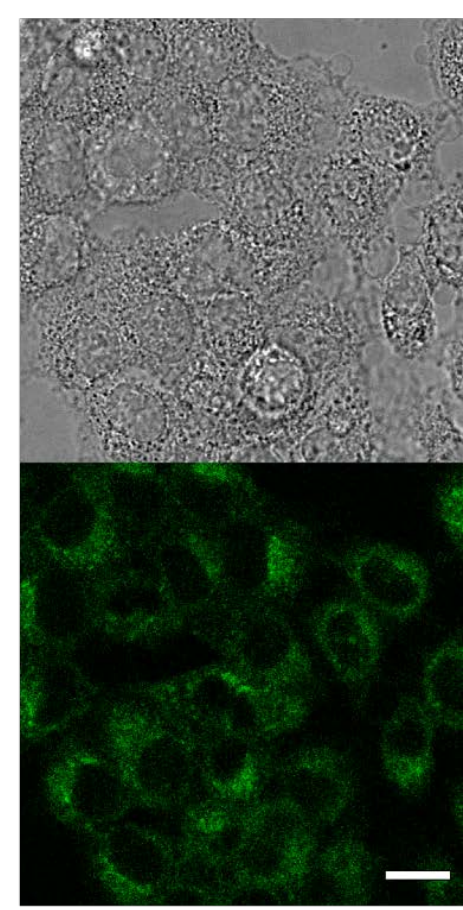

(c)

Figure 5. Confocal fluorescence images of HeLa cells without incubation with photosensitizers (a) and after incubation with Ce6 (b) and Ce6-biotin (c). Scale bars: $20 \mu \mathrm{m}$.

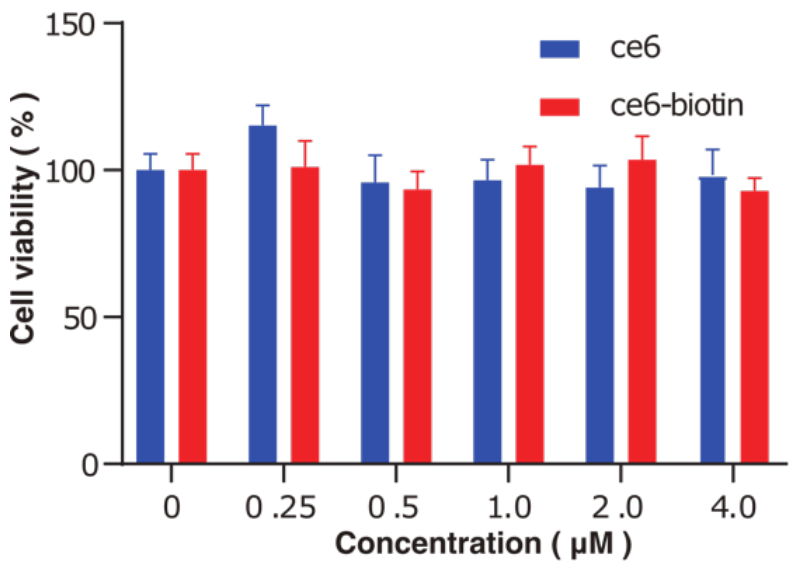

(a)

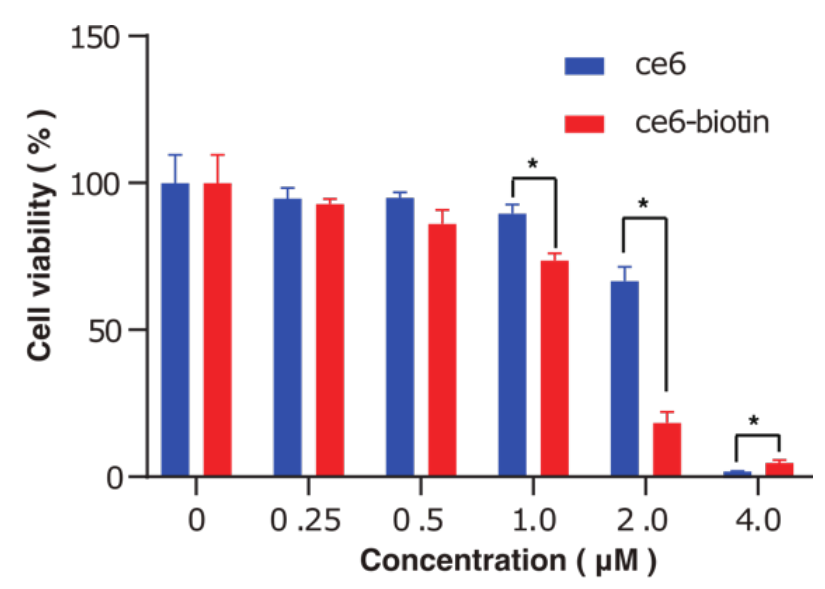

(b)

Figure 6. Cytotoxicity against HeLa cells of Ce6 and Ce6-biotin in the dark (a) or upon irradiation $((\mathbf{b}), \lambda=655 \mathrm{~nm})$. $p$-values $<0.05$ are denoted with asterisks $\left({ }^{*}\right)$. 


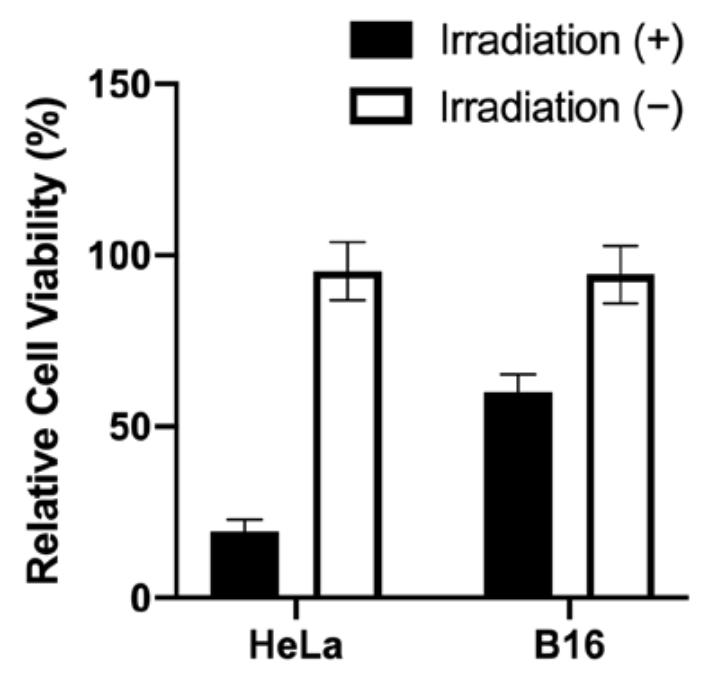

Figure 7. Cytotoxicity against HeLa $(\mathrm{BR}+)$ and $\mathrm{B} 16(\mathrm{BR}-)$ cells with and without irradiation $\left(20 \mathrm{~J} \cdot \mathrm{cm}^{-2}\right)$ after incubation with $2.0 \mu \mathrm{M}$ Ce6-biotin for $24 \mathrm{~h}$.

\section{Materials and Methods}

\subsection{Materials}

Chlorin e6, biotin, N-Hydroxybenzotrizole (HOBt), EDCI, N,N-Dimethylformamide (DMF), dichloromethane (DCM), trifluoroacetic acid (TFA), and 4-piperidinol, $N, N$ diisopropylethylamine (DIPEA) were obtained from Sigma-Aldrich (St. Louis, MO, USA). SOSG was purchased from Thermo Fisher Scientific, Inc. (Waltham, MA, USA). HeLa cells were purchased from the Type Culture Collection of the Chinese Academy of Sciences, Shanghai, China. High-glucose Dulbecco's modified Eagle medium (DMEM), TrypsinEDTA $(0.25 \%)$, heat-inactivated fetal bovine serum (FBS), and penicillin-streptomycin solution were purchased from Thermo Fisher Scientific, Inc. (Waltham, MA, USA).

\subsection{Synthesis of Ce6-Biotin}

Biotin as compound 1 (121.5 mg, $0.5 \mathrm{mmol})$, HOBt (80.65 mg, $0.6 \mathrm{mmol})$ and EDCI $(114 \mathrm{mg}, 0.6 \mathrm{mmol})$ were stirred in anhydrous DMF under ice-cold conditions for $15 \mathrm{~min}$. Mono-Boc-protected ethylene diamine $(0.5 \mathrm{mmol})$ dissolved in anhydrous DMF was slowly added. The corresponding reaction mixture was allowed to stir for $12 \mathrm{~h}$ at room temperature. When the reaction was finished, water $(100 \mathrm{~mL})$ was added, and the aqueous layer was extracted with DCM $(3 \times 10 \mathrm{~mL})$. The combined organic layer was dried over anhydrous $\mathrm{Na}_{2} \mathrm{SO}_{4}$ and concentrated under vacuum. The crude product obtained was purified by silica gel chromatography (with 6\% MeOH in DCM) to afford compound 2 as a white solid. Yield: $67.5 \mathrm{mg},(35 \%) .{ }^{1} \mathrm{H}-\mathrm{NMR}(300 \mathrm{MHz}, \mathrm{CD} 3 \mathrm{OH}) \delta 4.48-4.33(\mathrm{~m}, 1 \mathrm{H})$, 4.30-4.14 (m, 1H), 3.30-2.98 (m, 7H), 2.82 (dd, J = 12.6, 4.8 Hz, 1H), 2.60 (d, J = 12.5 Hz, 1H), $2.11(\mathrm{~d}, J=7.2 \mathrm{~Hz}, 2 \mathrm{H}), 1.74-1.46(\mathrm{~m}, 4 \mathrm{H}), 1.33(\mathrm{~s}, 9 \mathrm{H})$. Compound 2 was then dissolved in DCM/TFA (3:1) and stirred for $3 \mathrm{~h}$ at room temperature to obtain compound 3 . The mixture was concentrated under vacuum.

The obtained compound 3 was reacted with Ce6 without further purification. Then, Ce6 (10 mg, 1 eq.) was dissolved in DMF. EDCI (1.5 eq.), and compound 3 (1.4 eq.) and DIPEA were added to the reaction mixture. The mixture was stirred overnight at room temperature. The reaction was monitored by TLC. The reaction mixture was diluted with water and adjusted to $\mathrm{pH} 3$ with $5 \%$ citric acid aqueous solution and extracted with $\mathrm{CH}_{2} \mathrm{Cl}_{2}$ (three times). The $\mathrm{CH}_{2} \mathrm{Cl}_{2}$ layer was washed with brine and dried over anhydrous $\mathrm{Na}_{2} \mathrm{SO}_{4}$. Removal of the solvent under reduced pressure gave a crude product. The crude product was purified by prep-HPLC on an X Bridge C18 chromatographic column using a linear gradient from $30 \%$ to $40 \%$ acetonitrile in $\mathrm{MeCN} / \mathrm{H}_{2} \mathrm{O}\left(0.1 \% \mathrm{NH}_{4} \mathrm{HCO}_{3}\right)$ to obtain Ce6biotin. Yield: $2 \mathrm{mg}$, (13.8\%). ${ }^{1} \mathrm{H}-\mathrm{NMR}$ (400 MHz, DMSO) $\delta 9.78$ (s, 1H), 9.66 (s, 1H), 9.12 (s, $1 \mathrm{H}), 9.02(\mathrm{~s}, 1 \mathrm{H}), 8.35(\mathrm{dd}, J=17.8,11.7 \mathrm{~Hz}, 1 \mathrm{H}), 6.43(\mathrm{~d}, J=18.2 \mathrm{~Hz}, 1 \mathrm{H}), 6.13(\mathrm{~d}, J=12.0 \mathrm{~Hz}$, 
1H), 6.09 (s, 1H), $5.98(\mathrm{~s}, \mathrm{br}, 1 \mathrm{H}), 4.71(\mathrm{~d}, J=6.3 \mathrm{~Hz}, 1 \mathrm{H}), 4.56(\mathrm{~d}, J=6.8 \mathrm{~Hz}, 1 \mathrm{H}), 3.81(\mathrm{~d}$, $J=7.0 \mathrm{~Hz}, 2 \mathrm{H}), 3.53(\mathrm{~s}, 3 \mathrm{H}), 3.47$ (s, 3H), 3.05 (s, br, 4H), 2.23 (s, br, 2H), 1.95 (s, br, 3H), 1.66 $(\mathrm{t}, J=7.5 \mathrm{~Hz}, 3 \mathrm{H}), 1.60(\mathrm{~d}, J=6.4 \mathrm{~Hz}, 2 \mathrm{H}), 1.32(\mathrm{~s}, 1 \mathrm{H}), 1.20(\mathrm{~s}, 3 \mathrm{H}), 0.95$ (s, br, 3H). HR-MS found: $m / z$ : $865.4067[\mathrm{M}+\mathrm{H}]^{+}$, calcd for: $\mathrm{C}_{46} \mathrm{H}_{57} \mathrm{~N}_{8} \mathrm{O}_{7} \mathrm{~S}$. The purity was found to be $\sim 90 \%$ by HPLC analysis.

\subsection{Photophysical Measurement}

Absorption and fluorescence emission spectra were recorded by a UV-Vis spectrophotometer (Lambda 35, PerkinElmer Instruments, Waltham, MA, USA) and spectrofluorometer (F96, Lengguang Tech, Shanghai, China). For fluorescence measurements, the excitation wavelength was set at $400 \mathrm{~nm}$.

\subsection{Singlet-Oxygen Generation Measurement}

First, Ce6 and Ce6-biotin $(2 \mu \mathrm{M}, 990 \mu \mathrm{L})$ and SOSG $(0.5 \mathrm{mM}, 10 \mu \mathrm{L})$ were mixed in $1.5 \mathrm{~mL}$ centrifuge tubes. The final concentration of SOSG was $5 \mu \mathrm{M}$. After irradiation $\left(660 \mathrm{~nm}, 1 \mathrm{~W} \cdot \mathrm{cm}^{-2}\right)$ for different time periods $(0,1,2,4,8,12,16,20 \mathrm{~min})$, the fluorescence intensity was detected using a fluorescence spectrophotometer (F-4600, Hitachi, Tokyo, Japan).

Singlet-oxygen generation yield of Ce6-biotin $(2 \mu \mathrm{M})$ was evaluated by using SOSG as a probe molecule. Ce6 $(\Phi \Delta=0.75$ in PBS) was employed as a reference PS for singletoxygen quantum-yield calculations [31]. For each PS, the slope of emission maxima of SOSG at $530 \mathrm{~nm}$ versus the time graph was drawn. Finally, singlet-oxygen quantum yields were calculated according to the Equation (1) given below:

$$
\Phi_{\Delta}(\mathrm{PS})=\Phi_{\Delta}(\text { ref }) \times \frac{\mathrm{m}(\mathrm{PS})}{\mathrm{m}(\text { ref })} \times \frac{\mathrm{F}(\text { ref })}{\mathrm{F}(\mathrm{PS})} \times \frac{\mathrm{PF}(\text { ref })}{\mathrm{PF}(\mathrm{PS})}
$$

where PS represents Ce6-biotin; ref represents Ce6; $\mathrm{m}$ is the slope of emission maxima of SOSG at $530 \mathrm{~nm}$ versus time graph; $\mathrm{F}$ is the correction factor, which is given by $\mathrm{F}=1-10^{-\mathrm{OD} \mid}$ (OD, optical density, at the irradiation wavelength, which is $660 \mathrm{~nm}$ ); and $\mathrm{PF}$ is absorbed photonic flux in $\mu$ Einstein $\mathrm{dm}^{-3} \cdot \mathrm{s}^{-1}$. PF was ignored in the calculations, as both Ce6-biotin and Ce6 were irradiated with the same light source $\left(660 \mathrm{~nm}, 1 \mathrm{~W} \cdot \mathrm{cm}^{-2}\right)$.

\subsection{Cellular Uptake}

HeLa cells were maintained in high-glucose DMEM with $10 \%$ FBS at $37^{\circ} \mathrm{C}$ under a humidified $5 \% \mathrm{CO}_{2}$ atmosphere. HeLa cells $\left(3 \times 10^{5}\right)$ were seeded in 12-well plates and incubated to confluence. Then, the cells were incubated with the Ce6 and Ce6-biotin $(2 \mu \mathrm{M})$ for $0.5,1,2,4$, and $6 \mathrm{~h}$. The medium was carefully aspirated, then the cells were rinsed 3 times with PBS, trypsinized and collected by centrifugation, and then fixed with $4 \%$ paraformaldehyde for $30 \mathrm{~min}$. Cellular uptake was quantitatively measured with a BD LSRFortessa flow cytometer.

\subsection{Cytotoxicity}

MTT assay was utilized to evaluate the cytotoxicity of the Ce6 and Ce6-biotin against the HeLa cells. HeLa cells were seeded at $6 \times 10^{3}$ per/well in costar 96-well plates and incubated for $12 \mathrm{~h}$ to confluence. The cells were treated with various concentrations $(0.01-4 \mu \mathrm{M})$ of the Ce6 and Ce6-biotin for $24 \mathrm{~h}$ at $37^{\circ} \mathrm{C}$. Then, the cells were washed with PBS and refilled with culture medium. The cells were irradiated with an LED assay $\left(\lambda \approx 655 \mathrm{~nm}, 6.0 \mathrm{~mW} \cdot \mathrm{cm}^{2}\right)$ for $60 \mathrm{~min}$, and the total light dose was $20 \mathrm{~J} \cdot \mathrm{cm}^{-2}$. After $24 \mathrm{~h}$ incubation, MTT solution was added to each well, and the cells were incubated for another $4 \mathrm{~h}$. Then the MTT solutions were removed, and the wells were refilled with $100 \mu \mathrm{L}$ of DMSO. The cell viability date was obtained by measuring the absorbance at $570 \mathrm{~nm}$ and reference at $630 \mathrm{~nm}$ of each well using a Tecan i-control infinite 200Pro. Dark controls were measured using the above method without illumination. 


\subsection{Intracellular Fluorescence Images}

For confocal laser scanning microscopy, HeLa cells were seeded in a Lab-Tek chamber slide system (Thermo Fisher Scientific, Waltham, MA, USA) with $5 \times 10^{3}$ cells per well in DMEM $(200 \mu \mathrm{L})$ containing $10 \%$ FBS and cultured in a $1 \% \mathrm{O}_{2} / 5 \% \mathrm{CO}_{2}$ humidified atmosphere for $24 \mathrm{~h}$ at $37^{\circ} \mathrm{C}$. Then, cells were incubated with Ce6 and Ce6-biotin for $6 \mathrm{~h}$. After the cells were washed with PBS several times, they were stained with UltraCruz mounting medium (Santa Cruz Biotechnology, Dallas, TX, USA). Cellular uptake of Ce6 was measured using confocal laser scanning microscopy (STELLARIS Confocal Microscope, Leica, Germany).

\section{Conclusions}

Herein, we synthesized and characterized a new BR-targeted Ce6 compound for selective delivery of PSs to cancer cells that overexpressed the receptors of these ligands. Ce6-biotin exhibits highly efficient singlet-oxygen generation, which is similar to Ce6. For the BR-targeted PS, we detected an increase in its internalization in HeLa cells, indicating that Ce6-biotin can selectively accumulate in the BR-positive HeLa human cervical carcinoma cells, resulting in higher cellular uptake than its precursor, Ce6. Moreover, under irradiation with a red laser, Ce6-biotin exhibited stronger antitumor efficacy, combined with minimal dark toxicity. These findings demonstrate that Ce6-biotin is a promising PS for BR-positive-tumor-targeting PDT therapy and worthy of further investigation.

Supplementary Materials: The following are available online: Figure S1: The ${ }^{1} \mathrm{H}-\mathrm{NMR}$ of Bocprotected biotin (compound 2), Figure S2: The ${ }^{1} \mathrm{H}-\mathrm{NMR}$ of Ce6-biotin, Figure S3: The HR-MS of Ce6-biotin.

Author Contributions: Conceptualization, Y.T., Y.S. and S.W.; methodology, W.L. and X.M.; validation, J.Z. and Y.L.; formal analysis, W.L.; investigation, Y.J.; writing—original draft preparation, W.L.; writing-review and editing, X.M. and S.W.; funding acquisition, S.W. All authors have read and agreed to the published version of the manuscript.

Funding: We greatly appreciate the financial support from the National Natural Science Foundation of China (No. 82022034 and 81871420) and Jiangsu Province Natural Science Foundation of China (BK20200032).

Institutional Review Board Statement: Not applicable.

Informed Consent Statement: Not applicable.

Data Availability Statement: The data used to support the findings of this study are available from the corresponding author upon request.

Conflicts of Interest: The authors declare no conflict of interest.

Sample Availability: Samples of the compound, Ce6-biotin is available from the authors.

\section{References}

1. Deng, K.; Li, C.; Huang, S.; Xing, B.; Jin, D.; Zeng, Q.; Hou, Z.; Lin, J. Recent Progress in Near Infrared Light Triggered Photodynamic Therapy. Small 2017, 13, 1702299. [CrossRef] [PubMed]

2. Li, X.; Lee, S.; Yoon, J. Supramolecular Photosensitizers Rejuvenate Photodynamic Therapy. Chem. Soc. Rev. 2018, 47, 1174-1188. [CrossRef] [PubMed]

3. Li, X.; Lovell, J.F.; Yoon, J.; Chen, X. Clinical Development and Potential of Photothermal and Photodynamic Therapies for Cancer. Nat. Rev. Clin. Oncol. 2020, 17, 657-674. [CrossRef] [PubMed]

4. Wu, W.; Shao, X.; Zhao, J.; Wu, M. Controllable Photodynamic Therapy Implemented by Regulating Singlet Oxygen Efficiency. Adv. Sci. 2017, 4, 1700113. [CrossRef] [PubMed]

5. Kessel, D.; Reiners, J.J. Photodynamic Therapy: Autophagy and Mitophagy, Apoptosis and Paraptosis. Autophagy 2020, 16, 2098-2101. [CrossRef] [PubMed]

6. Luby, B.M.; Walsh, C.D.; Zheng, G. Advanced Photosensitizer Activation Strategies for Smarter Photodynamic Therapy Beacons. Angew. Chem. Int. Ed. 2019, 58, 2558-2569. [CrossRef]

7. Wang, Y.; Xie, Y.; Li, J.; Peng, Z.-H.; Sheinin, Y.; Zhou, J.; Oupický, D. Tumor-Penetrating Nanoparticles for Enhanced Anticancer Activity of Combined Photodynamic and Hypoxia-Activated Therapy. ACS Nano 2017, 11, 2227-2238. [CrossRef] 
8. Xu, J.; Zeng, F.; Wu, H.; Yu, C.; Wu, S. Dual-Targeting Nanosystem for Enhancing Photodynamic Therapy Efficiency. ACS Appl. Mater. Interfaces 2015, 7, 9287-9296. [CrossRef]

9. Li, W.; Yang, J.; Luo, L.; Jiang, M.; Qin, B.; Yin, H.; Zhu, C.; Yuan, X.; Zhang, J.; Luo, Z.; et al. Targeting Photodynamic and Photothermal Therapy to the Endoplasmic Reticulum Enhances Immunogenic Cancer Cell Death. Nat. Commun. 2019, 10, 3349. [CrossRef]

10. Jenni, S.; Sour, A.; Bolze, F.; Ventura, B.; Heitz, V. Tumour-Targeting Photosensitisers for One- and Two-Photon Activated Photodynamic Therapy. Org. Biomol. Chem. 2019, 17, 6585-6594. [CrossRef] [PubMed]

11. Li, K.; Dong, W.; Liu, Q.; Lv, G.; Xie, M.; Sun, X.; Qiu, L.; Lin, J. A Biotin Receptor-Targeted Silicon(IV) Phthalocyanine for in Vivo Tumor Imaging and Photodynamic Therapy. J. Photochem. Photobiol. 2019, 190, 1-7. [CrossRef] [PubMed]

12. Li, K.; Qiu, L.; Liu, Q.; Lv, G.; Zhao, X.; Wang, S.; Lin, J. Conjugate of Biotin with Silicon(IV) Phthalocyanine for Tumor-Targeting Photodynamic Therapy. J. Photochem. Photobiol. 2017, 174, 243-250. [CrossRef] [PubMed]

13. Singh, Y.; Durga Rao Viswanadham, K.K.; Kumar Jajoriya, A.; Meher, J.G.; Raval, K.; Jaiswal, S.; Dewangan, J.; Bora, H.K.; Rath, S.K.; Lal, J.; et al. Click Biotinylation of PLGA Template for Biotin Receptor Oriented Delivery of Doxorubicin Hydrochloride in 4T1 Cell-Induced Breast Cancer. Mol. Pharmaceutics 2017, 14, 2749-2765. [CrossRef]

14. Deshpande, N.U.; Jayakannan, M. Biotin-Tagged Polysaccharide Vesicular Nanocarriers for Receptor-Mediated Anticancer Drug Delivery in Cancer Cells. Biomacromolecules 2018, 19, 3572-3585. [CrossRef] [PubMed]

15. Raja, S.; Hamouda, A.E.I.; de Toledo, M.A.S.; Hu, C.; Bernardo, M.P.; Schalla, C.; Leite, L.S.F.; Buhl, E.M.; Dreschers, S.; Pich, A.; et al. Functionalized Cellulose Nanocrystals for Cellular Labeling and Bioimaging. Biomacromolecules 2021, 22, 454-466. [CrossRef]

16. Said, H.M. Biotin: Biochemical, Physiological and Clinical Aspects. In Water Soluble Vitamins; Stanger, O., Ed.; Subcellular Biochemistry; Springer Netherlands: Dordrecht, The Netherlands, 2012; Volume 56, ISBN 978-94-007-2198-2.

17. Isaac-Lam, M.; Hammonds, D. Biotinylated Chlorin and Its Zinc and Indium Complexes: Synthesis and In Vitro Biological Evaluation for Photodynamic Therapy. Pharmaceuticals 2017, 10, 41. [CrossRef] [PubMed]

18. Balçik-Erçin, P.; Çetin, M.; Göksel, M.; Durmuş, M. Improved Targeting for Photodynamic Therapy via a Biotin-Phthalocyanine Conjugate: Synthesis, Photophysical and Photochemical Measurements, and in Vitro Cytotoxicity Assay. New J. Chem. 2020, 44, 3392-3401. [CrossRef]

19. Hu, X.; Tian, H.; Jiang, W.; Song, A.; Li, Z.; Luan, Y. Rational Design of IR820- and Ce6-Based Versatile Micelle for Single NIR Laser-Induced Imaging and Dual-Modal Phototherapy. Small 2018, 14, 1802994. [CrossRef] [PubMed]

20. Zhu, Y.-X.; Jia, H.-R.; Chen, Z.; Wu, F.-G. Photosensitizer (PS)/Polyhedral Oligomeric Silsesquioxane (POSS)-Crosslinked Nanohybrids for Enhanced Imaging-Guided Photodynamic Cancer Therapy. Nanoscale 2017, 9, 12874-12884. [CrossRef] [PubMed]

21. O'Connor, A.E.; Gallagher, W.M.; Byrne, A.T. Porphyrin and Nonporphyrin Photosensitizers in Oncology: Preclinical and Clinical Advances in Photodynamic Therapy. Photochem. Photobiol. 2009, 85, 1053-1074. [CrossRef] [PubMed]

22. Huang, Z. A Review of Progress in Clinical Photodynamic Therapy. Technol Cancer Res. Treat 2005, 4, 283-293. [CrossRef] [PubMed]

23. Chen, H.; Waruna Jinadasa, R.G.; Jiao, L.; Fronczek, F.R.; Nguyen, A.L.; Smith, K.M. Chlorin E6 131:152-Anhydride: A Key Intermediate in Conjugation Reactions of Chlorin E6. Eur. J. Org. Chem. 2015, 2015, 3661-3665. [CrossRef]

24. Paul, S.; Heng, P.W.S.; Chan, L.W. Optimization in Solvent Selection for Chlorin E6 in Photodynamic Therapy. J. Fluoresc. 2013, 23, 283-291. [CrossRef] [PubMed]

25. Isaac-Lam, M.F.; Hammonds, D.M. Synthesis and Photodynamic Activity of Vitamin-Chlorin Conjugates at Nanomolar Concentrations against Prostate Cancer Cells. ACS Omega 2019, 4, 21712-21723. [CrossRef] [PubMed]

26. Yu, Y.; Zhang, Z.; Wang, Y.; Zhu, H.; Li, F.; Shen, Y.; Guo, S. A New NIR-Triggered Doxorubicin and Photosensitizer Indocyanine Green Co-Delivery System for Enhanced Multidrug Resistant Cancer Treatment through Simultaneous Chemo/Photothermal/Photodynamic Therapy. Acta Biomater. 2017, 59, 170-180. [CrossRef]

27. Wang, Q.; Yu, L.; Wong, R.C.H.; Lo, P.-C. Construction of Cathepsin B-Responsive Fluorescent Probe and Photosensitizer Using a Ferrocenyl Boron Dipyrromethene Dark Quencher. Eur. J. Med. Chem. 2019, 179, 828-836. [CrossRef] [PubMed]

28. Iqbal, Z.; Chen, J.; Chen, Z.; Huang, M. Phthalocyanine-Biomolecule Conjugated Photosensitizers for Targeted Photodynamic Therapy and Imaging. CDM 2015, 16, 816-832. [CrossRef] [PubMed]

29. Taquet, J.; Frochot, C.; Manneville, V.; Barberi-Heyob, M. Phthalocyanines Covalently Bound to Biomolecules for a Targeted Photodynamic Therapy. CMC 2007, 14, 1673-1687. [CrossRef] [PubMed]

30. Schmitt, J.; Heitz, V.; Sour, A.; Bolze, F.; Kessler, P.; Flamigni, L.; Ventura, B.; Bonnet, C.S.; Tóth, É. A Theranostic Agent Combining a Two-Photon-Absorbing Photosensitizer for Photodynamic Therapy and a Gadolinium(III) Complex for MRI Detection. Chem. Eur. J. 2016, 22, 2775-2786. [CrossRef] [PubMed]

31. Adimoolam, M.G.; Vijayalakshmi, A.; Nalam, M.R.; Sunkara, M.V. Chlorin E6 Loaded Lactoferrin Nanoparticles for Enhanced Photodynamic Therapy. J. Mater. Chem. B 2017, 5, 9189-9196. [CrossRef] [PubMed] 